\title{
Research on the Microstructure and Property of an Anion Rubber Modified Asphalt
}

\author{
Wei Hong, ${ }^{1}$ Qingshan Li, ${ }^{2}$ Guoquan Guan, ${ }^{3}$ Youbo Di, ${ }^{1}$ Jing Sun, \\ Tifeng Jiao, ${ }^{4}$ and Guangzhong Xing ${ }^{2}$ \\ ${ }^{1}$ College of Textile Engineering and Art, Taiyuan University of Technology, Taiyuan 030024, China \\ ${ }^{2}$ State Key Laboratory of Metastable Materials Science and Technology (Yanshan University), Qinhuangdao 066004, China \\ ${ }^{3}$ Hesen Chemical Technology Co. Ltd., Chengdu 610072, China \\ ${ }^{4}$ Hebei Key Laboratory of Applied Chemistry, Yanshan University, Qinhuangdao 066004, China
}

Correspondence should be addressed to Wei Hong; weih@ysu.edu.cn

Received 9 March 2013; Accepted 28 April 2013

Academic Editor: Christian Brosseau

Copyright (C) 2013 Wei Hong et al. This is an open access article distributed under the Creative Commons Attribution License, which permits unrestricted use, distribution, and reproduction in any medium, provided the original work is properly cited.

\begin{abstract}
The anion rubber modified asphalt (ARMA) mixture was first successfully developed with a unique process. In the development process, rubber and asphalt were mixed in the same proportion. Furthermore, the microstructure and modification mechanism of the material were characterized by SEM, FT-IR, TG, and XRD tests. The mechanical property of the mixture was also tested in accordance with the relevant standards. In the end, the material's capacity of releasing anion was measured by DLY-6A232 atmospheric ion gauge. The results indicated that the addition of anion additive into the rubber modified asphalt (RMA) was a mere physical mixture, and the anion additives and rubber particles uniformly dispersed in the ARMA. The addition of anion additive could improve the thermal stability of the RMA. Compared with the traditional asphalt pavement material, the ARMA material shows excellent mechanical properties as well as the ability of releasing anion. Moreover, the material has enormous economic and social benefits by taking full advantage of a large amount of waste tires, thus improving the road surrounding environment.
\end{abstract}

\section{Introduction}

With the rapid development of the Chinese auto industry and the continuous improvement of people's living quality, car ownership is increasing, which results in the problem of dealing with many waste tires. According to the statistics, the number of the waste tires is 2.8451 million tons in 2012, and it will reach 3.2007 million tons in 2013. Such a large number of waste tires bring about heavy social and environmental burden. The recycling of waste tires is, hence, extremely urgent. At present, the major methods in dealing, with the waste tires include stacking (or tamping), burning and recycling. The application of crumb rubber in road construction, which is also regarded as a better choice for handling a large amount of waste tires, has become a research and application emphasis globally $[1,2]$.

Anion concentration is listed as an important parameter to measure the air quality, and appropriate anion concentration is beneficial to human health and environmental improvement [3-6]. ARMA (anion rubber modified asphalt) possesses the double advantage of excellent performance and green environmental protection.

\section{Experiment}

\subsection{Preparation of the ARMA}

2.1.1. Main Materials. 90\# matrix asphalt was obtained from Asphalt Company (Shengli oilfield, Dongying, Shandong). 20-100 $\mu \mathrm{m}$ recycled rubber powder was purchased from Fangdahuanyu Co, Ltd. (Dongguan). The anion additive with a diameter of $15-400 \mathrm{~nm}$ was bought from Yanda Qicai Technology Limited Company, and the additive was selfprepared.

2.1.2. Preparation of ARMA. A certain amount of matrix asphalt was firstly melted and dehydrated, and then the rubber powder and additive were added in accordance with 
TABLE 1: Main instruments and equipments.

\begin{tabular}{lcccc}
\hline & Serial number & Equipment name & Equipment model \\
\hline & 1 & Automatic Asphalt Penetrometer & DF-4 \\
Main instruments and equipments & 2 & Asphalt Softening Point Apparatus & SYD-2806E \\
& 3 & Asphalt Ductility Instrument & YSH-3 & DV II \\
& 4 & Brookfield Viscometer & LBH-1 \\
& 5 & Asphalt Film Oven & DLY-6A232 \\
\hline
\end{tabular}

TABLE 2: The test result on the mechanical properties of the ARMA.

\begin{tabular}{|c|c|c|c|c|}
\hline \multicolumn{2}{|c|}{ Indicators } & Unit & Method & Test result \\
\hline \multirow{2}{*}{ Penetration } & $25^{\circ} \mathrm{C}$ & $0.1 \mathrm{~mm}$ & T0604-2000 & 76 \\
\hline & $15^{\circ} \mathrm{C}$ & $0.1 \mathrm{~mm}$ & T0604-2000 & 54 \\
\hline Softening point & Ring-and-ball apparatus & ${ }^{\circ} \mathrm{C}$ & T0604-2000 & 60 \\
\hline Ductility & $15^{\circ} \mathrm{C}, 5 \mathrm{~cm} / \mathrm{min}$ & $\mathrm{cm}$ & T0604-1993 & 41.5 \\
\hline Elasticity resuming & $25^{\circ} \mathrm{C}$ & $\%$ & T0604-2000 & 58.0 \\
\hline Rotary sticky degree & $177^{\circ} \mathrm{C}$ & $\mathrm{Pa} \cdot \mathrm{s}$ & T0604-2000 & 1.6 \\
\hline \multicolumn{5}{|c|}{ Asphalt membrane heating test (T0609-1993) } \\
\hline Quality variation & & $\%$ & T0609-1993 & 0.09 \\
\hline Rudimental penetration ratio & $25^{\circ} \mathrm{C}$ & $\%$ & T0604-2000 & 75 \\
\hline Rudimental ductility & $177^{\circ} \mathrm{C}$ & $\mathrm{cm}$ & Т0605-1993 & 9.3 \\
\hline
\end{tabular}

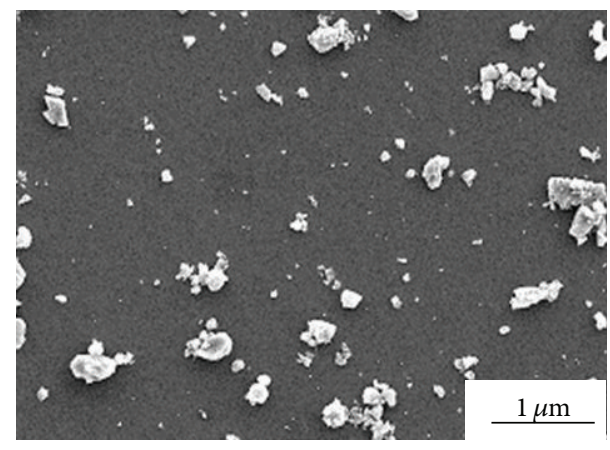

FIGURE 1: The SEM image of anion additive.

the formula. The rubber and asphalt were combined in an appropriate ratio (a high proportion modified adulteration technique was utilized so that the proportion of rubber to asphalt could reach up to $1: 1$ ) and churned until they were well mixed, and then the mixture was heated up to $180^{\circ} \mathrm{C}$. Further, by using a high shear scattered emulsifying machine, the mixture was then homogenized for $30 \mathrm{~min}$ at a temperature of $170-190^{\circ} \mathrm{C}$ and a speed of $4000-6000 \mathrm{r} / \mathrm{min}$. And then the required amount of anion additive was added, followed by blending for another $30 \mathrm{~min}$. The mixture was then cooled to $160 \pm 10^{\circ} \mathrm{C}$ and placed for $30 \mathrm{~min}$; the anion rubber modified asphalt was thus obtained. The particle size of anion additive is micron/nanolevel, and the immiscible system is uniform and stable, thereby being applied to production [7].

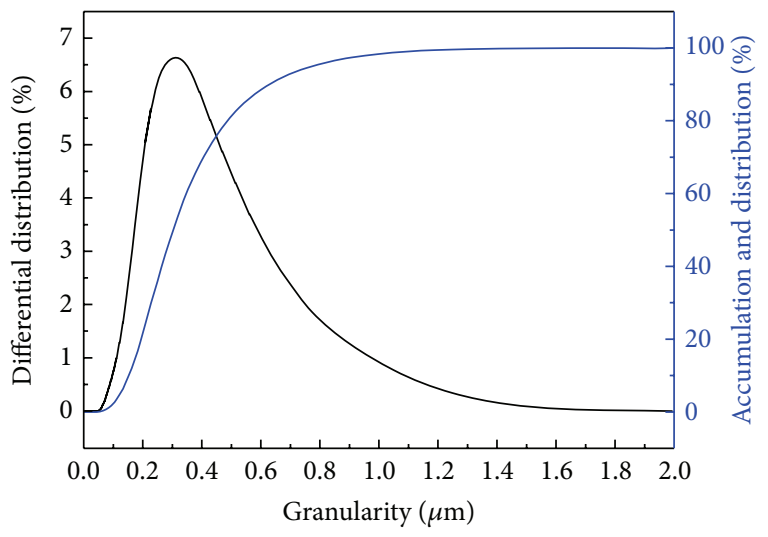

FIGURE 2: Anion additive size distribution.

TABLE 3: The experimental results of the TGA of RMA and ARMA.

\begin{tabular}{lccc}
\hline Sample & $\begin{array}{c}\text { The initial temperature } \\
\text { of mass loss }\left({ }^{\circ} \mathrm{C}\right)\end{array}$ & $\begin{array}{c}\text { Mass loss } \\
(\%)\end{array}$ & $\begin{array}{c}\text { Residues } \\
(\%)\end{array}$ \\
\hline ARMA & 296 & 63.42 & 35.58 \\
RMA & 290 & 65.96 & 34.04 \\
\hline
\end{tabular}

\subsection{Tests}

2.2.1. Study of Microstructure and Modification Mechanism. The morphology of the sample with $3 \%$ anion additive was investigated by S-4800-based SEM. The respective infrared spectroscopy analysis of anion additive, RMA (rubber modified asphalt), and ARMA (the content of anion additive was $3 \%$ ) was carried out by employing the E55 + FRA106-based 


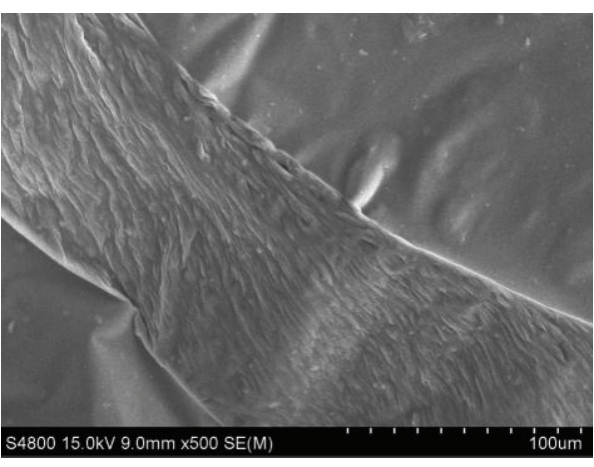

(a)

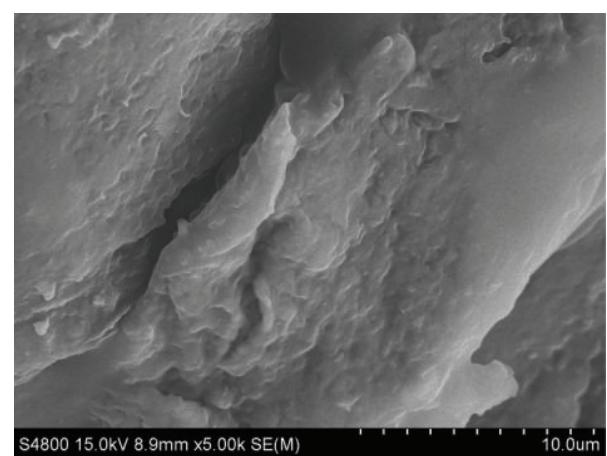

(b)

Figure 3: The SEM image of the ARMA: $(\mathrm{a}) \times 500$; (b) $\times 5000$.

TABLE 4: Anion release test results for laboratory samples and asphalt pavement.

\begin{tabular}{|c|c|c|c|c|}
\hline Test location & $\begin{array}{c}\text { Maximum anion } \\
\text { concentration }\left(\text { anions } / \mathrm{cm}^{3}\right)\end{array}$ & $\begin{array}{c}\text { Average anion concentration } \\
\left(\text { anions } / \mathrm{cm}^{3}\right)\end{array}$ & $\begin{array}{c}\text { Temperature } \\
\left({ }^{\circ} \mathrm{C}\right) \\
\end{array}$ & $\begin{array}{c}\text { Relative humidity } \\
(\%)\end{array}$ \\
\hline \multicolumn{5}{|l|}{ Laboratory } \\
\hline Sample 1 & -1190 & -1076 & \multirow{2}{*}{20} & \multirow{2}{*}{50} \\
\hline Sample 2 & -1150 & -968 & & \\
\hline \multicolumn{5}{|l|}{ Anion asphalt pavement } \\
\hline Test point 1 & -1400 & -530 & & \\
\hline Test point 2 & -1430 & -1320 & & \\
\hline Common asphalt pavement & & & 25 & 50 \\
\hline Test point 1 & -230 & -88 & & \\
\hline Test point 2 & -280 & -100 & & \\
\hline
\end{tabular}

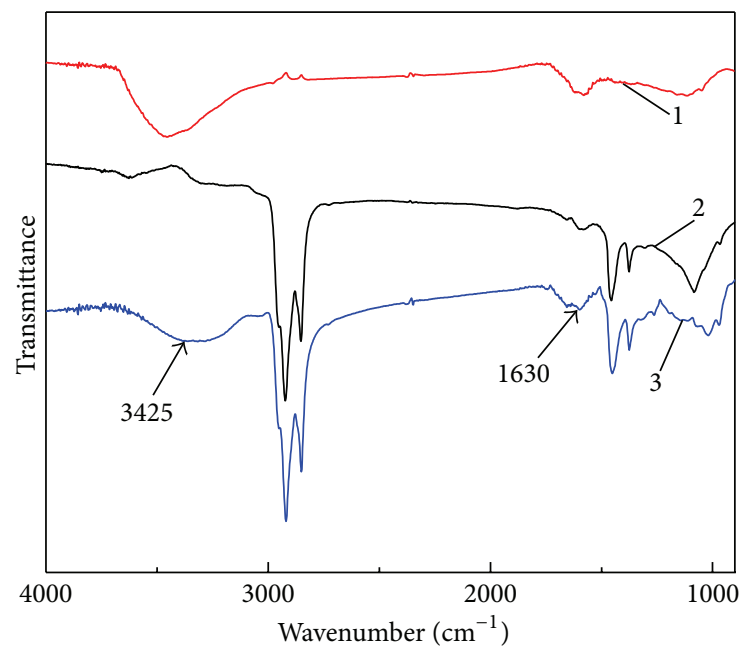

FIgURE 4: The FTIR spectra of anion additives, RMA, and ARMA: (1) anion additives; (2) RMA; (3) ARMA.

Fourier transform infrared/Raman spectroscopy. The thermal gravimetric analysis of RMA and ARMA (the content of anion additive was 3\%) was, respectively, conducted by the NETZSCH-type differential thermal-thermal gravimetric

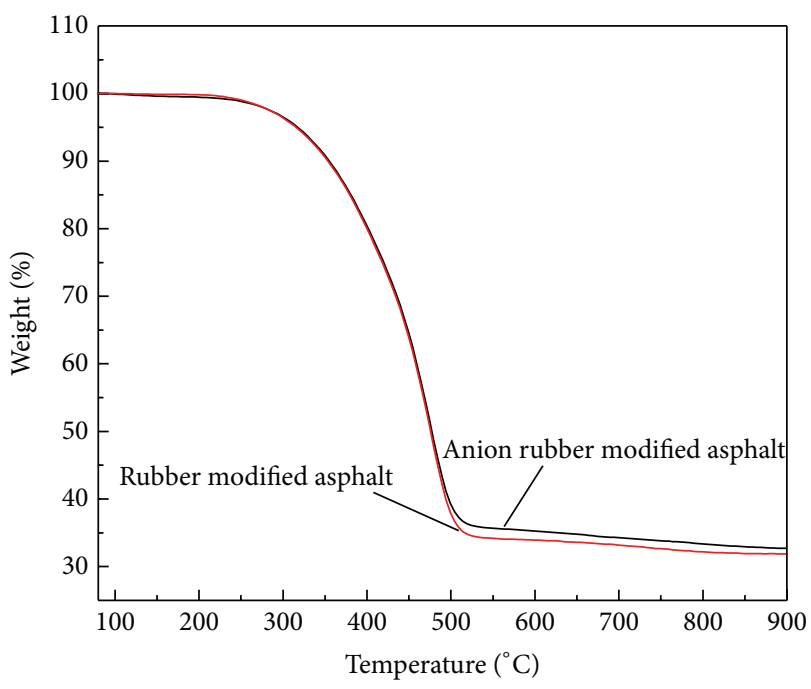

FIgURE 5: The TGA curves of the RMA and ARMA.

analyzer. The heating rate was $10^{\circ} \mathrm{C} / \mathrm{min}$, scanning temperatures from $0^{\circ} \mathrm{C}$ to $900^{\circ} \mathrm{C}$. The $\mathrm{X}$-ray diffraction analysis on RMA and ARMA samples was, respectively, carried out by the Japanese D-max-2500 X-ray diffraction with the condition of measuring range being $10^{\circ}-60^{\circ}$ and the scan speed being 


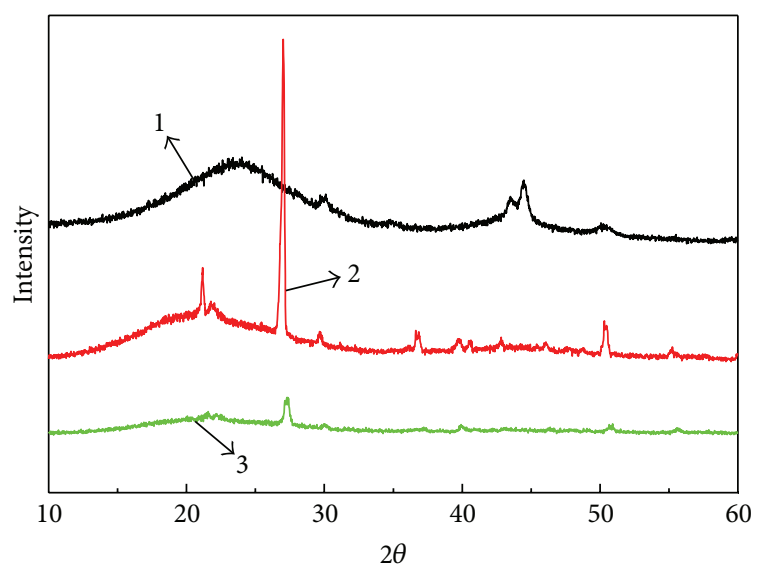

FIGURE 6: The XRD patterns of ARMA, anion additive, and RMA: (1) ARMA; (2) anion additive; (3) RMA.

$2^{\circ} / \mathrm{min}$. The distribution of the anion additive particle size was measured by the laser particle size analyzer (Rise-2008, Jinan Rise Science \& Technology Co. Ltd.).

2.2.2. The Performance Test of ARMA. In accordance with the Standard Test Methods of Bitumen and Bituminous Mixtures for Highway Engineering (JTJ052-2000) and Technical Specifications for Construction of Highway Asphalt Pavements (JTG F40-2004), the regular performance of the sample was tested, the proportion of the asphalt mixture was designed, and the road capability was evaluated [8-10].

The equipments required in the current experiment are listed in Table 1.

2.2.3. Anion Release Performance Test. The amount of the released anion on a natural ARMA pavement (with the anion additive content of $3 \%$ ), paved by the ARMA mixture, was tested by the DLY-6A232 Air Ion Detector (Lianteng Electronic Co. Ltd., Jinling Branch Road no. 1, Jinfeng Development Zone, Zhangzhou, Fujian, China). The test result was compared with both the lab test results and the test results on other pavements, to get the evaluative conclusion [11-13].

\section{Results and Discussion}

3.1. The Regular Performance Test on ARMA. The result of the conventional performance on ARMA was shown in Table 2.

In accordance with the industry standard Asphalt Rubber for Highway Engineering, the evaluation on the test result of the technical index about the regular performance of the ARMA was carried out since there are no national standards for the evaluation of the RMA [14]. With reference to the relevant regulations in the standards, the test results on the ARMA all met the standards; that is, the sample was well qualified.

3.2. Study on the Microstructure and Modification Mechanism. According to Figures 1 and 2, the average particle size of the anion additive is $0.356 \mu \mathrm{m}$, and the particle size of $97 \%$ particles is below $0.878 \mu \mathrm{m}$, which means that the additive is a micro-nanoscale material and could be used as the nuclei in the A-PCM1030, thereby improving the crystallinity of the material.

It can be seen from Figure 3(a) that the anion additive and rubber articles are distributed uniformly in the asphalt matrix and no apparent agglomeration happened. And Figure 3(b) shows that the anion additive, rubber particles, and asphalt exhibited excellent adhesion. To be specific, the rubber has partially swelled, and excellent adhesion appeared in different phase inferences.

The FTIR spectra of the anion additive, RMA, and ARMA were presented in Figure 4. As is shown in this figure, at $3425 \mathrm{~cm}^{-1}$, the characteristic peak is the stretching vibration absorption band for $\mathrm{O}-\mathrm{H}$, whereas at $1630 \mathrm{~cm}^{-1}$, the characteristic peak is the variable angle absorption peak for $\mathrm{H}-\mathrm{OH}$. The characteristic peak of the ARMA in these two places is obviously enhanced than that of the RMA, which demonstrated the stable existence of the anion additive in the ARMA; and no novel characteristic peaks occur within this region [15].

The above analysis demonstrated that the addition of anion additive into rubber modified asphalt belongs to a physical mixture process. No new functional groups are generated, and there are only Van der Waals forces between the components. Moreover, the particle diameter of the anion additive is nanoscale, and the immiscible system is uniform and stable, which is suitable for practical application.

Figure 5 shows the TGA curves of RMA and ARMA, and in accordance with this figure, the curves of the two samples are basically the same except the slight difference in such aspects as the initial temperature of mass loss and residual of the quality.

According to Figure 5, the initial temperature of mass loss, mass loss $\left(290-580^{\circ} \mathrm{C}\right)$, and residues $\left(580^{\circ} \mathrm{C}\right)$ of the two samples were calculated, and the result was listed in Table 3.

The initial temperature of the mass loss of ARMA is close to that of the RMA. The mass loss in the main decomposition temperature range of the ARMA is slightly lower than that of the RMA. It indicated that the addition of the anion additive has little effect on the thermal stability of the RMA, except slightly improving the heat resistance of the RMA.

On the one hand, anion additive could increase the residues of the material due to its excellent stability at high temperature; on the other hand, strong intermolecular interactions were formed between macromolecules and micro/nanoscale particles of anion additives, which increased the activation energy of the polymer in the decomposition process, thus increasing the thermal performance of the material.

Figure 6 describes the XRD patterns of ARMA, anion additive, and RMA. To be more specific, in the XRD pattern of the RMA, the characteristic diffraction peak of the pure RMA emerged at $2 \theta=23^{\circ}$ and $2 \theta=27^{\circ}$, which is related to the semicrystalline generated in the RMA, while according to the XRD pattern of the anion additive, the characteristic diffraction peak of the anion additive occurred at $2 \theta=21^{\circ}$ 


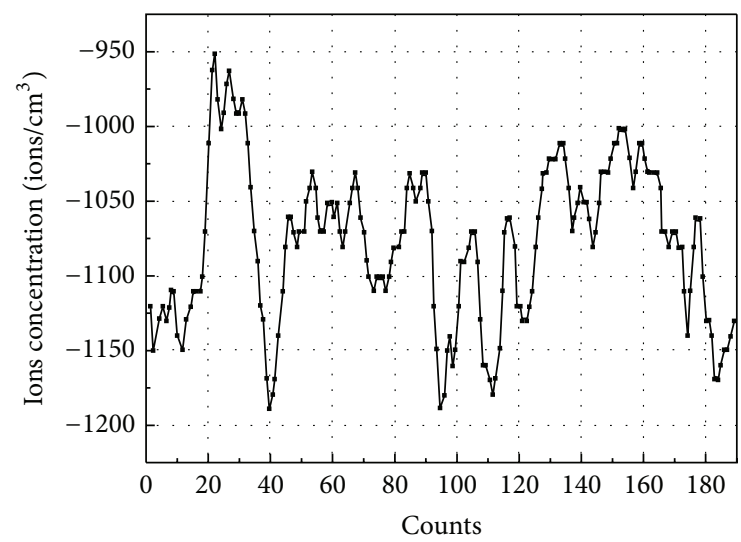

(a)

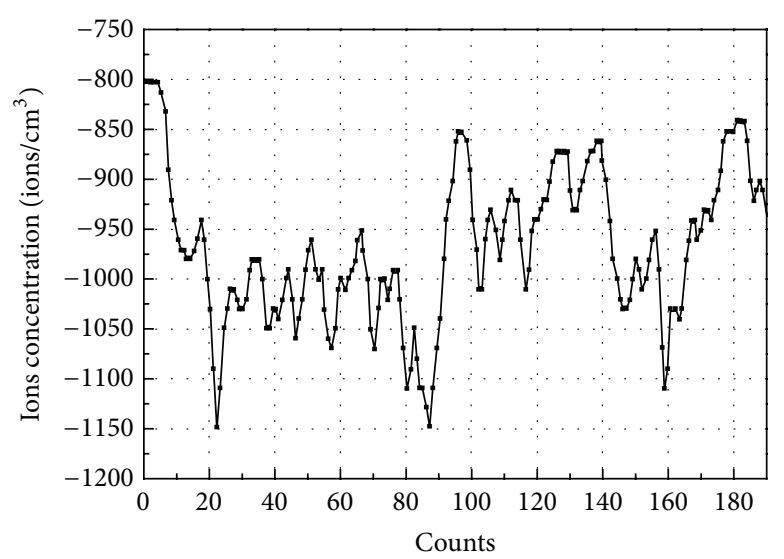

(b)

FIGURE 7: Anion release test in laboratory.

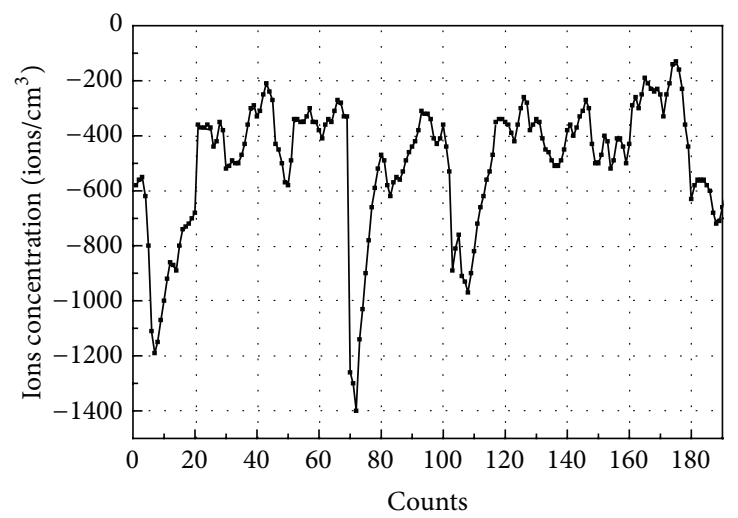

(a)

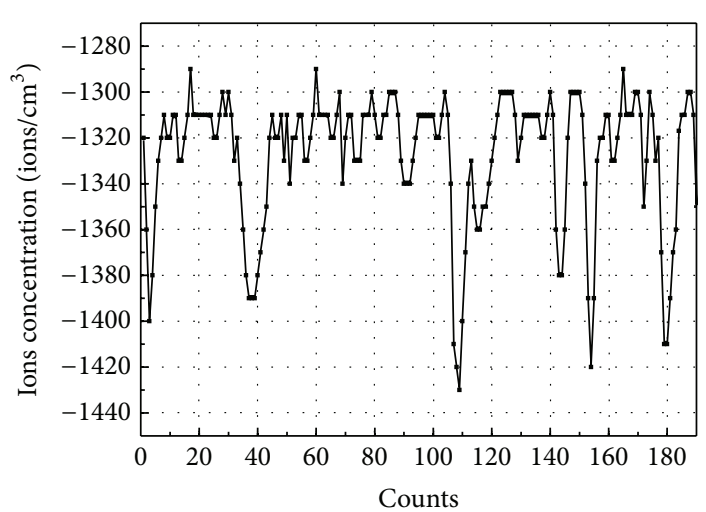

(b)

Figure 8: Anion asphalt pavement anion release test.

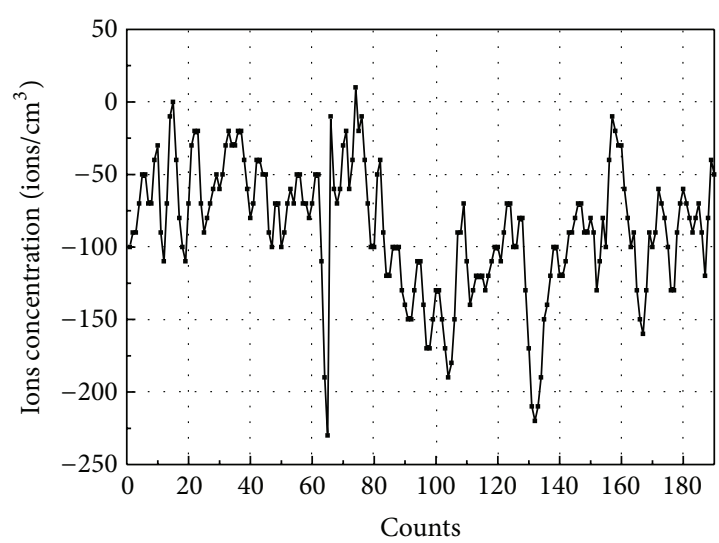

(a)

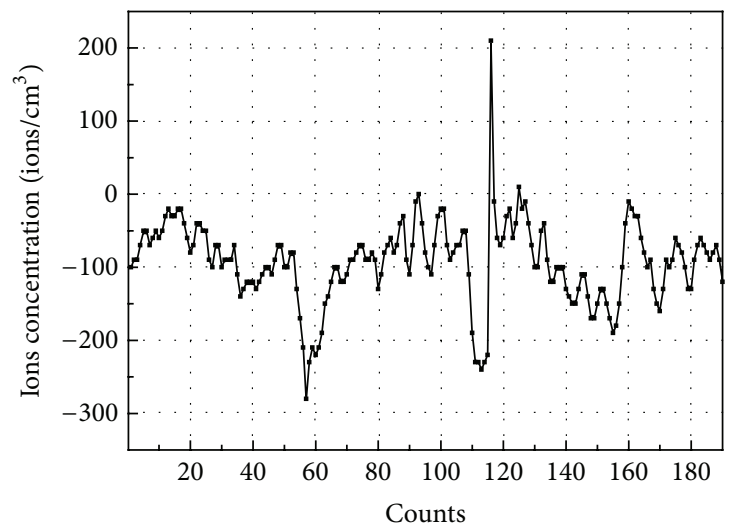

(b)

FIGURE 9: Common road asphalt pavement anion release test.

and $2 \theta=26^{\circ}$, which demonstrated that anion additive has excellent crystallinity. It can be seen that at $2 \theta=24^{\circ}$, the characteristic diffraction peak of the ARMA (the content of the anion additive is $3 \%$ ) is significantly stronger than that of the RMA. Furthermore, the XRD pattern of the ARMA showed that a new wider diffraction peak appeared at $2 \theta=$ $44^{\circ}$. This is due to the nuclei role that the micro-nanoscale particles of anion additives played, which improved the degree of crystallinity of the RMA and at the same time decreased the crystal size to converge $[16,17]$. 
3.3. The Anion Release Performance Evaluation of ARMA. Test location: certain pavement in Chengdu. Test environment: after rain, $25^{\circ} \mathrm{C}$, sunny. The test results and curves were listed in Table 4 and Figures 7, 8, and 9.

It can be seen that the air anion concentration of the anion asphalt pavement is about 1000 anions $/ \mathrm{cm}^{3}$, and the maximum value could reach -1430 anions $/ \mathrm{cm}^{3}$. Whereas that of the common asphalt pavement is lower than 100 anions $/ \mathrm{cm}^{3}$.

\section{Conclusions}

This paper presents a new technology to incorporate a high percentage of modified recycled material $(1: 1)$. Specifically, the production of 10 tons modified asphalt could make full use of 5 tons waste tire rubber powder, which has important environmental protection significance in eliminating the black pollution of waste tires. Only intermolecular forces exist between rubber and asphalt as well as between anion additive and RMA; no novel chemical changes happened, and no new substances or groups have been generated. The anion additives dispersed uniformly in the ARMA and no agglomeration occurred; the rubber particles uniformly dispersed in the ARMA and the swelling happened. The addition of the anion additive improved the thermal stability of the RMA as well as the degree of crystallinity of the RMA and meanwhile decreased the crystal size to be converging. The ARMA possessed such features as large high temperature stiffness modulus, high softening point, and strongly creep resistance. The addition of the anion additive could benefit the pavement with the anion release property, which can effectively improve the surrounding environment of the road [18-20].

\section{Acknowledgments}

This work was supported by the National Natural Science Foundation of China (50943027) and the China Textile Industry Association, school-enterprise cooperation special funds, (2012120).

\section{References}

[1] W. M. Lv, Asphalt Mixture Design Theory and Methods, Tongji University Press, Shanghai, China, 2001.

[2] S. L. Aleksandrova, A. I. Kartashevskii, and V. E. Tirakyan, "Compatibility of rubbers with asphalt components and properties of artificial compounded asphalts," Chemistry and Technology of Fuels and Oils, vol. 17, no. 7, pp. 419-422, 1981.

[3] A. P. Krueger, “The biological effects of air ions," International Journal of Biometeorology, vol. 29, no. 3, pp. 205-206, 1985.

[4] T. Ryushi, I. Kita, T. Sakurai et al., "The effect of exposure to negative air ions on the recovery of physiological responses after moderate endurance exercise," International Journal of Biometeorology, vol. 41, no. 3, pp. 132-136, 1998.

[5] T. D. Thanh, N. D. Mao, N. T. K. Ngan et al., "Study structure and properties of nanocomposite material based on unsaturated polyester with clay modified by poly (ethylene oxide)," Journal of Nanomaterials, vol. 2012, Article ID 841813, 5 pages, 2012.
[6] J. Yu, M. Jaroniec, H. Yu et al., "Synthesis, characterization, properties, and applications of nanosized photocatalytic materials," Journal of Nanomaterials, vol. 2012, Article ID 783686, 3 pages, 2012.

[7] W. Hong, Q. Li, Z. Lv, G. Guan, and G. Xing, "Preparation and properties of anion rubber-modified asphalt," in Proceedings of the International Conference on Materials for Renewable Energy and Environment (ICMREE '11), pp. 932-935, May 2011.

[8] Highway Asphalt Pavement Construction Technical Standard, JTGF40-2004, Communications Press, Beijing, China, 2004.

[9] The Test Criterion for Highway Project Pitch and Pitch Compounds, JTJ052-2000, Communications Press, Beijing, China, 2000.

[10] X. D. Wang, Guide for Design and Construction of Asphalt Rubber and Mixture, Communications Press, Beijing, China, 2008.

[11] Y. Ma, Q. Li, Y. Di, and M. Zhang, "Research on superfine wool surface texture modified in biochemistry," Advanced Materials Research, vol. 96, pp. 189-196, 2010.

[12] L. Xie and Q. S. Li, "Research on nature rubber modification," World Rubber Industry, vol. 35, pp. 1-4, 2008.

[13] L. Xie, Q. S. Li, and M. Zhao, "The design and exploiture of anion elastomer," China Rubber Science and Technology Market, vol. 9, pp. 21-24, 2008.

[14] Asphalt Rubber For Highway Engineering, JT/T 798-2011, Communications Press, Beijing, China, 2011.

[15] W. Hong, Q. S. Li, G. Q. Quan et al., "Pavement performance and application of anion rubber-modified asphalt," Chinese Science Bulletin, vol. 57, pp. 2323-2328, 2012.

[16] P. Xi, X. Gu, B. Cheng, and Y. Wang, "Preparation and characterization of a novel polymeric based solid-solid phase change heat storage material," Energy Conversion and Management, vol. 50, no. 6, pp. 1522-1528, 2009.

[17] W. Hong, Q. S. Li, Y. Ma et al., "Research progress on polymer nanocomposite phase change storage energy material," Polymer Bulletin, vol. 137, pp. 94-98, 2010.

[18] J. T. Yeh, H. H. Hsiung, W. Wei, P. Zhu, K. N. Chen, and T. Jiang, "Negative air ion releasing properties of tourmaline/bamboo charcoal compounds containing ethylene propylene diene terpolymer/polypropylene composites," Journal of Applied Polymer Science, vol. 113, no. 2, pp. 1097-1110, 2009.

[19] X. M. Wang, Q. S. Li, S. T. Qi et al., "The release anion polymer natural asphalt composites," China Patent CN102199358A, 2011.

[20] B. F. Li, Q. S. Li, and X. M. Wang, "The asphalt concrete pavement materials of release anions," China Patent CN102199017A, 2011. 

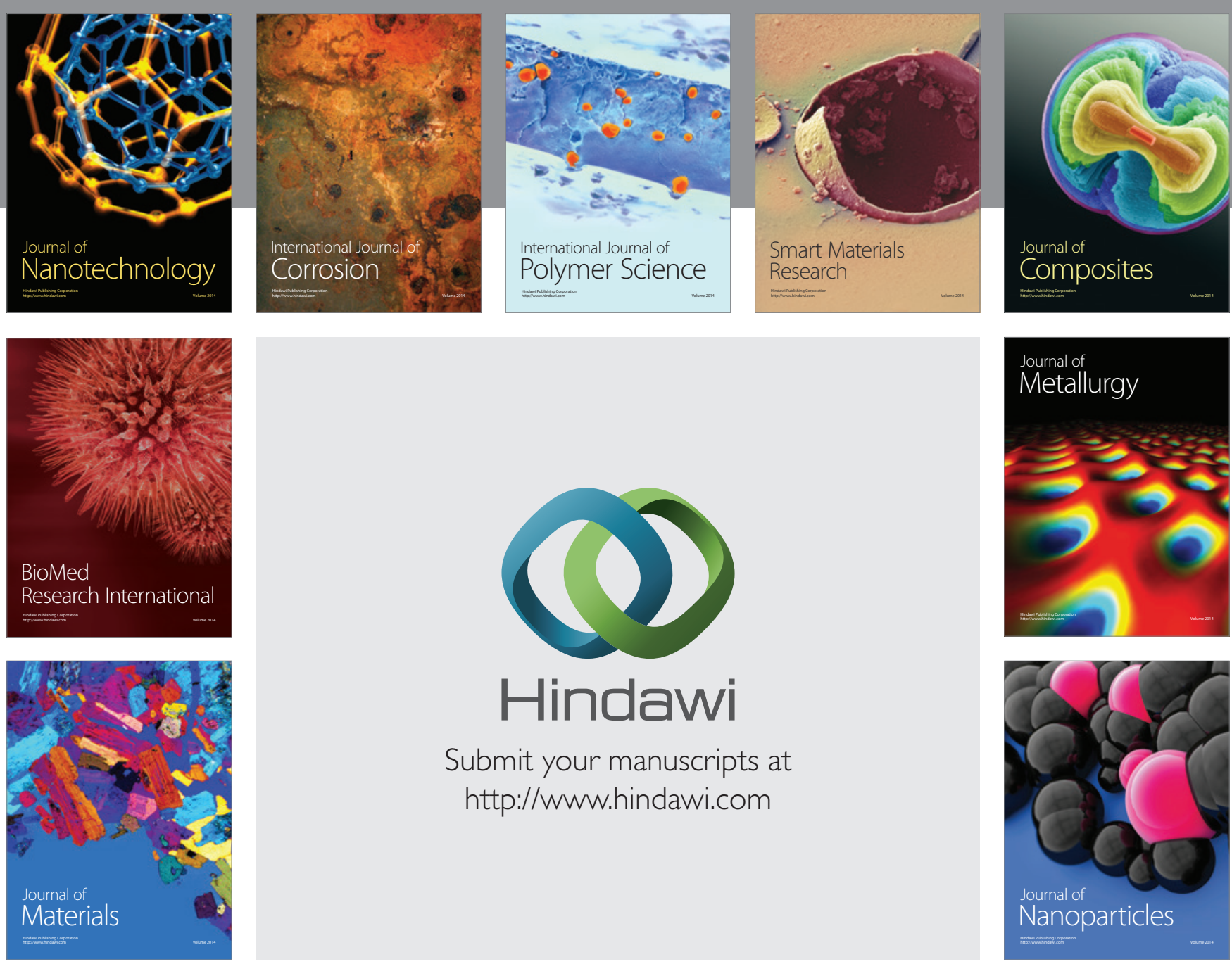

Submit your manuscripts at http://www.hindawi.com
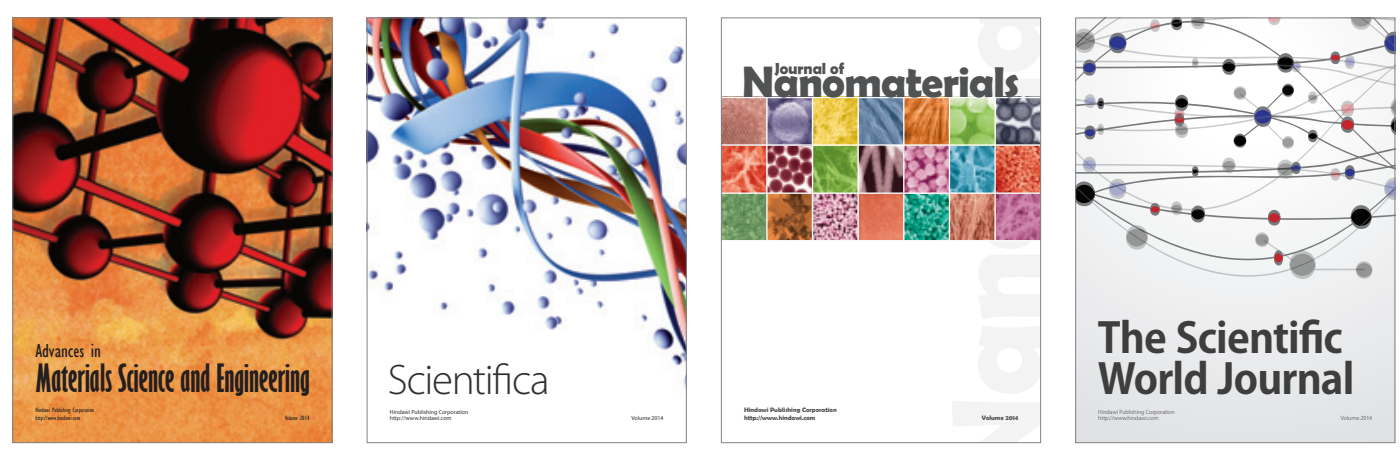

\section{The Scientific World Journal}
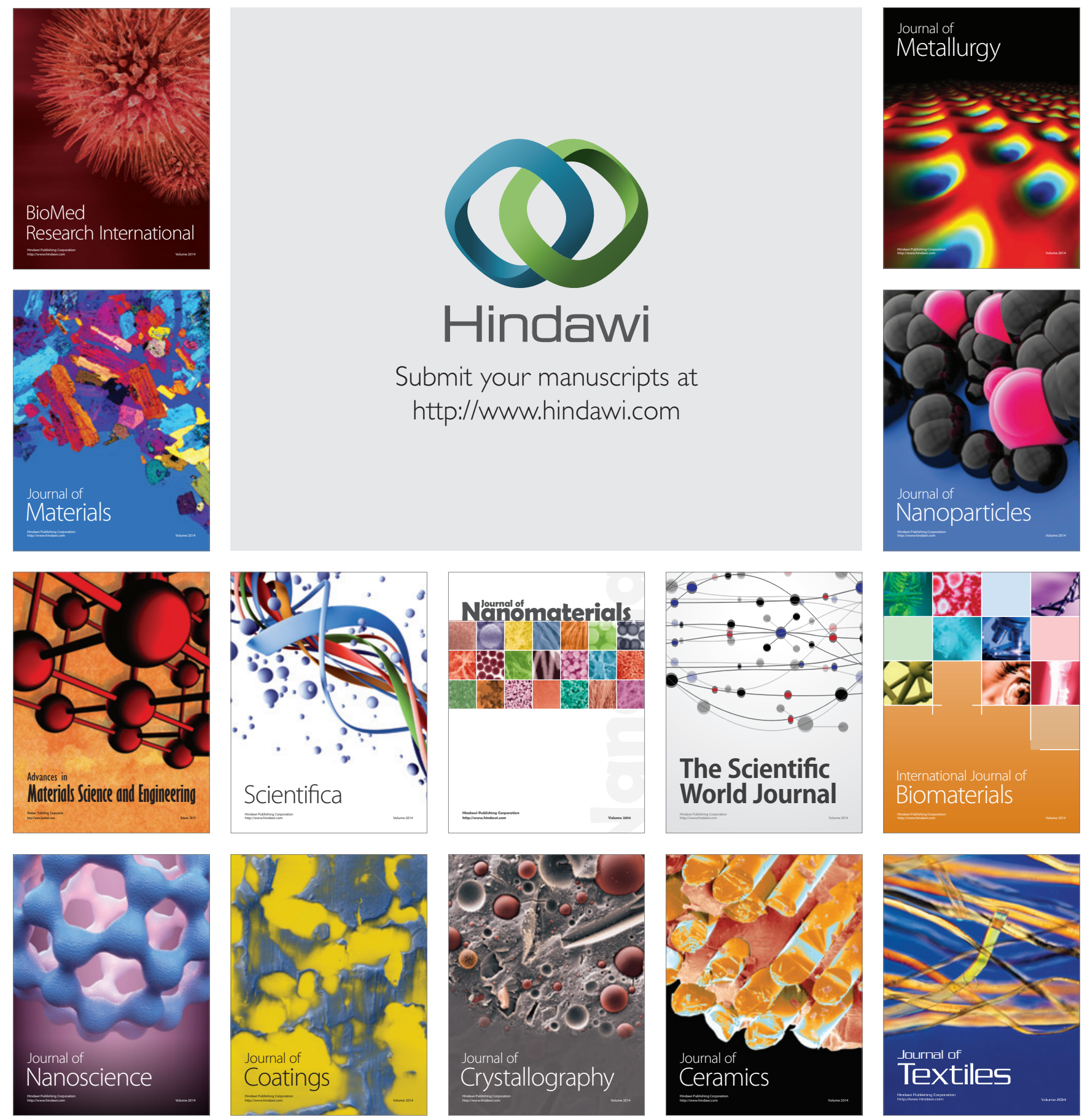